\title{
Antitumor and Cancer-preventative Function of Fucoxanthin: A Marine Carotenoid
}

\author{
YOSHIKO SATOMI \\ Faculty of Pharmaceutical Sciences, Suzuka University of Medical Science, Suzuka, Japan
}

\begin{abstract}
Fucoxanthin is a marine carotenoid mainly found in brown seaweeds. Its antitumor and cancer-preventative function has been extensively investigated. Investigations have indicated that fucoxanthin and its metabolite fucoxanthinol induce $G_{1}$ cell-cycle arrest and apoptosis in various cell lines and can inhibit cancer development in animal models. It is imperative that the underlying mechanism of action of fucoxanthin be elucidated in order to facilitate the development of cancer-prevention strategies in humans. Key molecules that require consideration include mitogen-activated protein kinase, growth arrest and DNA damage-inducible 45, AP-1 transcription factor, nuclear factor-kappa $B$ and several others, including cell cyclerelated molecules for $G_{1}$ cell-cycle arrest and the $B$ cell lymphoma-2 family, X-linked inhibitor of apoptosis, cellular inhibitor of apoptosis protein and AKT serinelthreonine kinase/phosphatidylinositol-3-kinase for apoptosis. In this review, the mechanisms by which fucoxanthin exerts its antitumor and cancer-preventative action in cell lines and mouse models is discussed, in addition to the potential use of fucoxanthin as a promising compound for cancer prevention.
\end{abstract}

Fucoxanthin is a red- or orange-colored carotenoid pigment that is produced in brown seaweeds and some microalgae (1$3)$. In humans, dietary fucoxanthin is mainly metabolized to fucoxanthinol, the deacetylated form of fucoxanthin $(4,5)$, and which is considered to be an active form of fucoxanthin. The chemical structure of fucoxanthin and fucoxanthinol is shown

This article is freely accessible online.

Correspondence to: Yoshiko Satomi, Faculty of Pharmaceutical Sciences, Suzuka University of Medical Science, 3500-3, Minamitamagaki, Suzuka, Mie 513-8670. Japan. E-mail: satomi@suzuka-u.ac.jp

Key Words: Fucoxanthin, carotenoid, antitumor activity, cancerpreventative activity, review. in Figure 1. Fucoxanthin possesses a unique chemical structure that includes an allene bond, 5,6-monoepoxide and acetylated group. Fucoxanthin is one of the most abundant carotenoids and fucoxanthin-containing brown algae, such as wakame (Undaria pinnatifida) and kombu (Laminaria japonica), are commonly consumed in Asia. Recent studies have revealed several health benefits of fucoxanthin, including antiinflammatory, anti-obesity, anti-diabetes, hepato-protective and cardiovascular-protective activities, in addition to anticancer activity $(2,6)$. With regard to the anticarcinogenic effect of fucoxanthin, it is well-known that fucoxanthin exerts tumorinhibitory effects in various cancer cells and mouse models. In order to clarify the anticancer effect of fucoxanthin, it is crucial to understand the underlying mechanism of action. In this review, the effects of fucoxanthin on cancer are summarized and the proposed mechanisms suggested by many researchers accounting for these are detailed.

\section{Fucoxanthin Inhibits Tumor Cell Growth by Inducing $G_{1}$ Cell-cycle Arrest With/ Without Apoptosis in Various Tumor Cells}

The antitumor effects of fucoxanthin are summarized in Figure 2.

$G_{1}$ cell-cycle arrest with/without apoptosis. Fucoxanthin has been mainly observed to induce $\mathrm{G}_{1}$ cell-cycle arrest in many tumor cell lines. Okuzumi et al. found that 5-10 $\mu \mathrm{g} / \mathrm{ml}(7.6-$ $15.2 \mu \mathrm{M})$ of fucoxanthin caused arrest during the $\mathrm{G}_{0} / \mathrm{G}_{1}$ phase of the cell cycle, and was accompanied with a decrease in $M Y C N$ proto-oncogene expression in human neuroblastoma GOTO cells (7).

Das et al. observed that fucoxanthin induced cell-cycle arrest during the $\mathrm{G}_{0} / \mathrm{G}_{1}$ phase in a dose- $(25$ and $50 \mu \mathrm{M})$ and time- $(24$ and $48 \mathrm{~h}$ ) dependent manner, and that apoptosis was induced at a high concentration $(50 \mu \mathrm{M})$ and at a later time $(48 \mathrm{~h})$ in human colon carcinoma WiDr cells (8). They also found that the increase in $\mathrm{p} 21^{\mathrm{WAF} 1 / \mathrm{CIP} 1}$, a cyclin-dependent kinase (CDK)inhibitory protein, and decreased phosphorylation levels of RB 
<smiles>CC(=O)OC1CC(O)CC2(C)OC2(C)CC(=O)C(C)=CC=CC(C)=CC=CC=C(C)C=CC=C(C)C=C2C(C)(O)CC(O)CC2(C)C(C)(C)C1</smiles>

Fucoxanthin<smiles>C/C=C(C)\C=C\C=C\C=C\C(C)=C\C=C\C=C(C)\C(C)=C\CC1(O)C(C)CC(O)CC1(C)C</smiles>

\section{Fucoxanthinol}

Figure 1. Chemical structures of fucoxanthin and fucoxanthinol.

transcriptional corepressor (RB), were dose-dependent. Furthermore, the increase in another CDK inhibitory protein $\mathrm{p} 27^{\mathrm{KIP} 1}$ and decrease in CDK4 and cyclin D, which phosphorylate the $\mathrm{RB}$ protein, were observed at high concentrations of fucoxanthin $(50$ and $75 \mu \mathrm{M})$. They speculated that $\mathrm{p} 21^{\mathrm{WAF} 1 / \mathrm{CIP} 1}$ plays a key role in $\mathrm{G}_{0} / \mathrm{G}_{1}$ arrest and that $\mathrm{p} 27^{\mathrm{KIP} 1}$ may be important for apoptosis by fucoxanthin. Another of their studies showed that $25 \mu \mathrm{M}$ of fucoxanthin induced cellcycle arrest during the $\mathrm{G}_{0} / \mathrm{G}_{1}$ phase in $\mathrm{HepG}_{2}$ human hepatocarcinoma cells (9). The induction of cell-cycle arrest was accompanied by a decrease in phosphorylated forms of RB without reducing the RB protein level, although $\mathrm{p} 21^{\mathrm{WAF} 1 / \mathrm{CIP} 1}$ and $\mathrm{p} 27^{\mathrm{KIP} 1}$ levels remained unchanged. The kinase activity of the cyclin D/CDK4 complex and protein level of cyclin D were also reduced by fucoxanthin. They suggested that downregulation of cyclin D may be an important factor in the action of fucoxanthin. Yu et al. found that $\mathrm{G}_{2} / \mathrm{M}$ arrest and apoptosis were induced by fucoxanthin $(50$ and $75 \mu \mathrm{M})$ in human gastric adenocarcinoma MGC-803 cells (10). Their study showed that fucoxanthin reduced the expression of cyclin B1 and survivin, and they suggested that these factors might contribute to the action of fucoxanthin. Since fucoxanthin usually induces $G_{0} / G_{1}$ arrest, the mechanism by which fucoxanthin induced $\mathrm{G}_{2} / \mathrm{M}$ arrest but not $\mathrm{G}_{1}$ arrest in MGC-803 cells should be clarified.

Ishikawa et al. showed that fucoxanthin $(10 \mu \mathrm{M})$ and fucoxanthinol $(5 \mu \mathrm{M})$, a metabolite of fucoxanthin, induced cell-cycle arrest during the $G_{1}$ phase and caspase-dependent apoptosis in adult T-cell leukemia cells (11). The reduction in cell cycle-related proteins such as cyclin D1, cyclin D2, CDK4 and CDK6, and the induction of DNA damage-inducible $45 \alpha$
(GADD45 $\alpha$ ), were observed concomitantly. A reduction in apoptosis-related proteins such as B-cell lymphoma-2 (BCL2), $\mathrm{X}$-linked inhibitor of apoptosis (XIAP), cellular inhibitor of apoptosis protein 2 (CIAP2) and survivin was also observed. Additionally, they speculated that the effects of fucoxanthin and fucoxanthinol might be mediated through the inactivation of transcription factor nuclear-factor kappa B (NF-kB) or AP1 transcription factor (AP1). Another study by the same group revealed that fucoxanthin $(2.5$ and $5 \mu \mathrm{M})$ and fucoxanthinol (1.25 and $2.5 \mu \mathrm{M}$ ) induced cell-cycle arrest during the $\mathrm{G}_{1}$ phase at low concentration and caspase-dependent apoptosis at high concentration in Burkitt's and Hodgkin's lymphoma cells (12). The decrease in cyclin D1, cyclin D2, BCL2, XIAP and CIAP2 protein levels was associated with suppression of $\mathrm{NF}-\mathrm{kB}$ activity. They supposed that major roles were played by the down-regulation of NF-kB-dependent cell survival proteins in apoptosis, and down-regulation of cyclin D in cellcycle arrest, as induced by fucoxanthin and fucoxanthinol. They also observed that fucoxanthin (5 and $10 \mu \mathrm{M})$ and fucoxanthinol $(2.5$ and $5 \mu \mathrm{M})$ induced $\mathrm{G}_{1}$ cell-cycle arrest and caspase-dependent apoptosis in primary effusion lymphoma cells (13). Concomitantly, the expression of BCL-xL, XIAP, survivin, cyclin D2, CDK4, CDK6 and c-MYC protooncogene protein were reduced, and inactivation of $\mathrm{NF}-\mathrm{kB}$, AP1 and AKT serine/threonine kinase (AKT) was found in the cells, some of which are heat-shock protein 90 (HSP90) client proteins the expression of which was restored by treatment with a proteasome inhibitor. They speculated that the effects of fucoxanthin and fucoxanthinol might be related to inhibition of HSP90 chaperon function. 


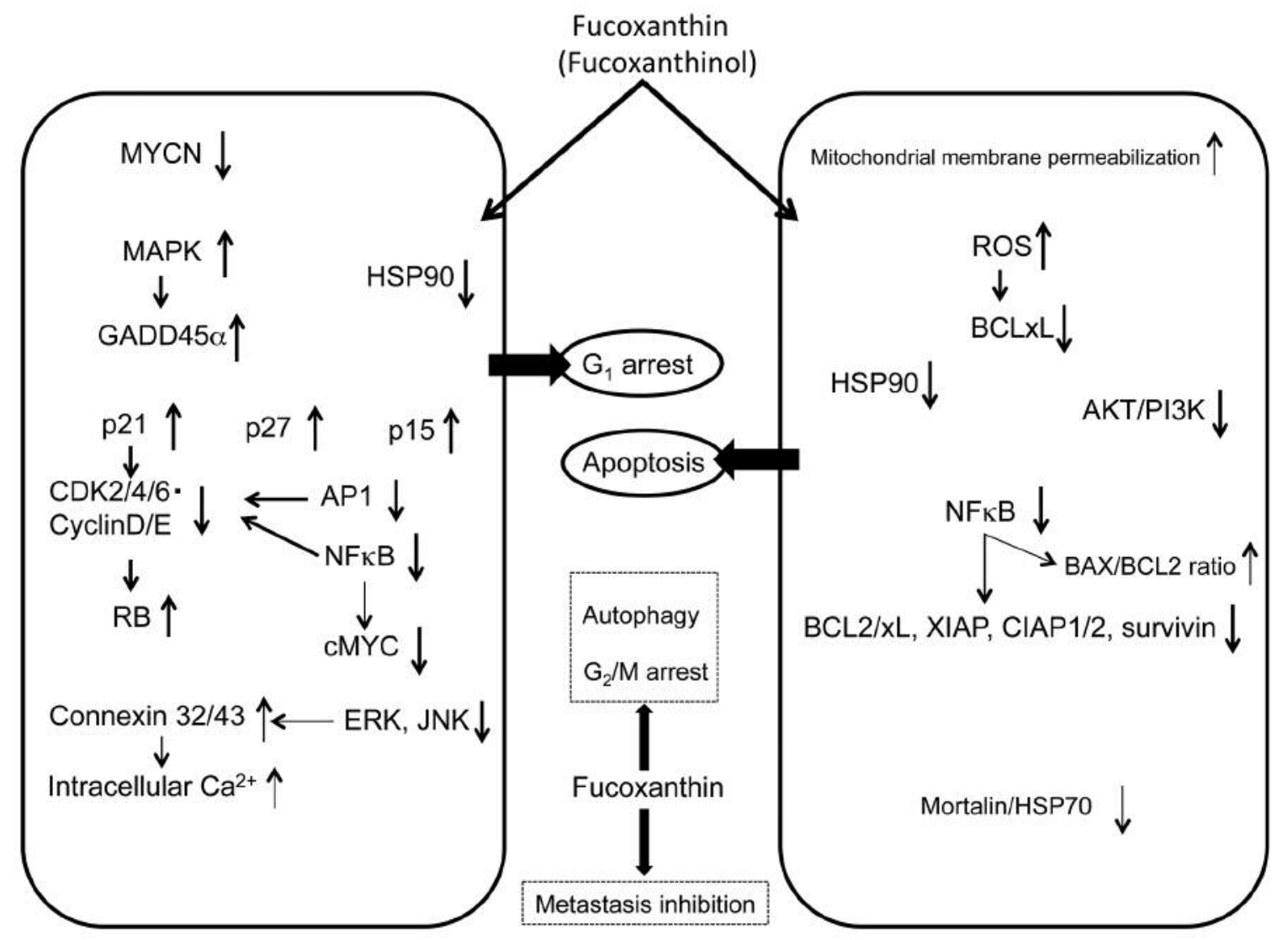

Figure 2. Antitumor effects of fucoxanthin and associated factors. $\uparrow$ Indicates induction or activation. $\downarrow$ Indicates reduction or inactivation. Arrows between factors indicate former factors affect latter factors. Thick arrows indicate that several research groups have observed these effects.

Kim et al. revealed that fucoxanthin $(50,100$ and $200 \mu \mathrm{M})$ caused caspase-dependent apoptosis following $\mathrm{G}_{0} / \mathrm{G}_{1}$ arrest in mouse melanoma B16F10 cells (14). Observations of cells showed a decrease in phosphorylated RB, cyclin D1, cyclin $\mathrm{D} 2$ and $\mathrm{CDK} 4$, and an increase in $\mathrm{p} 15^{\mathrm{INK} 4 \mathrm{~B}}$ and $\mathrm{p} 27^{\mathrm{KIP} 1}$ in addition to a decrease in BCL-xL, CIAP1, CIAP2 and XIAP. Wang et al. reported that 5 and $10 \mu \mathrm{M}$ of fucoxanthin induced cell-cycle arrest during the $\mathrm{G}_{0} / \mathrm{G}_{1}$ phase by upregulation of $\mathrm{p} 21^{\mathrm{WAF} 1 / \mathrm{CIP} 1}$ and down-regulation of CDK2, CDK4, cyclin D1 and cyclin E in human bladder cancer T24 cells (15). Additionally, treatment of cells with 20 and $40 \mu \mathrm{M}$ of fucoxanthin induced caspase-dependent apoptosis accompanied by a decrease in mortalin (a member of the HSP70 family inhibiting p53 function) and its decrease resulted in reactivation of $\mathrm{p} 53$. Liu et al. reported that fucoxanthin $(1-20 \mu \mathrm{M})$ caused cell-cycle arrest during the $\mathrm{G}_{0} / \mathrm{G}_{1}$ phase and apoptosis in SK-Hep-1 human hepatoma cells (16). These effects were associated with enhancement of gap junctional intercellular communication (GJIC) and an increase in connexin 43 and connexin 32 expression, as well as intracellular calcium level. A decrease in the phosphorylated forms of extracellular signal-regulated kinase (ERK) and c-Jun N-terminal kinase (JNK) was observed in the cells. They supposed that fucoxanthin increased intracellular calcium levels by GJIC enhancement and then caused cell-cycle arrest and apoptosis. Hou et al. found that fucoxanthin $(10,20$ and $40 \mu \mathrm{M})$ caused $\mathrm{G}_{0} / \mathrm{G}_{1}$ arrest accompanied by an increase in $\mathrm{p} 21^{\mathrm{WAF} 1 / \mathrm{CIP} 1}$ and decrease in cyclin D1 and CDK2 protein levels in human epithelial cervical cancer HeLa cells (17). They simultaneously observed that fucoxanthin induced autophagy associated with a reduction in phosphorylated AKT and its downstream proteins $\mathrm{p} 53$, phosphorylated forms of p70S6K and mechanistic target of rapamycin, and recorded an increase in phosphatase and tensin homolog PTEN.

Fucoxanthin (3.8-5.5 $\mu \mathrm{M})$ induced G1 cell-cycle arrest accompanied by induction of the GADD45A gene and activation of mitogen activated protein kinase (MAPK) pathways in $\mathrm{HepG}_{2}$, human prostate cancer DU145 and LNCap cells (18-20). MAPKs responsible for these effects were dependent on cell type. p38 MAPK was negatively associated with the fucoxanthin-mediated induction of 
Table I. Anticarcinogenic effects of fucoxanthin .

\begin{tabular}{lccc}
\hline & Cancer type & Method of administration & Effect \\
\hline Carcinogenesis models & Duodenal & Oral & Inhibition \\
& Skin & Topical application & Oral \\
& Colon & Oral & Apoptosis \\
\hline \multirow{2}{*}{ Lenograft models } & Lung metastasis of melanoma cells & Intraperitoneal injection & Oral \\
\cline { 2 - 4 } & Sarcoma, osteosarcoma & Oral & Oral \\
\cline { 2 - 4 } & Melanoma & Oral & \\
& Lymphoma & Cervical cancer & \\
\end{tabular}

GADD 45A followed by $\mathrm{G}_{1}$ arrest in $\mathrm{HepG}_{2}$ cells, and JNK was positively associated with that in DU145 cells. On the other hand, p38 and ERK1/2 were negatively and JNK positively implicated in the induction of GADD45A and $\mathrm{G}_{1}$ arrest by fucoxanthin in LNCap cells.

Apoptosis. Kotake-Nara et al. reported that fucoxanthin $(20 \mu \mathrm{M})$ induced DNA fragmentation as indicated by a TdT-mediated dUTP nick end labeling method using human prostate cancer cells PC-3, DU145 and LNCap cells (21). Furthermore, they observed that fucoxanthin $(10 \mu \mathrm{M})$ induced caspase-dependent apoptosis in human promyelocytic leukemia HL-60 cells via loss of mitochondrial membrane potential (22). Another study of theirs showed that fucoxanthin $(20 \mu \mathrm{M})$ induced caspasedependent apoptosis accompanied by a decrease in BCL2associated $\mathrm{X}(\mathrm{BAX})$ and BCL2 protein levels in PC-3 cells (23). They suggested that fucoxanthin might induce apoptosis by modulating the ratio of BAX/BCL2. Hosokawa et al. reported that fucoxanthin (at least $7.6 \mu \mathrm{M}$ for $48 \mathrm{~h}$ ) caused DNA fragmentation indicating apoptosis, which was partially inhibited by a caspase inhibitor, and that it reduced the BCL2 protein level in Caco-2 human colon cancer cells, all of which led them to conclude that BCL2 may contribute to apoptosis induced by fucoxanthin (24). In another report by the same group, fucoxanthin $(25 \mu \mathrm{M})$ was shown to induce apoptosis in MCF-7 human breast cancer cells (25). Apoptosis was induced by $5-40 \mu \mathrm{g} / \mathrm{ml}$ of fucoxanthin $(7.6-60.7 \mu \mathrm{M})$, as indicated by DNA ladder and morphological changes in lung cancer cells NSCLC-N6 and A549 cells (26).

Zhang et al. observed that $20 \mu \mathrm{M}$ of fucoxanthin significantly induced apoptosis accompanied by caspase- 3 activation at $72 \mathrm{~h}$ in EJ-1 human bladder cancer cells (27). Kim et al. reported that fucoxanthin induced caspase-dependent apoptosis following reactive oxygen species (ROS) generation and BCL-XL reduction in HL-60 cells (28). They indicated that ROS generation by fucoxanthin played a crucial role. Ganesan et al. showed that $10 \mu \mathrm{M}$ of fucoxanthin caused apoptosis and caspase- 3 activation in HL-60 cells (29). Fucoxanthin $(0.5 \mu \mathrm{M})$ was shown to induce caspase-dependent apoptosis with an increase in BAX and reduction in BCL2, phosphatidylinositol3-kinase (PI3K) and a phosphorylated form of AKT in HeLa cells (30). The authors also found NF-kB inactivation and a decrease in its translocation to the nucleus from the cytoplasm in cells treated with fucoxanthin. Rwigemera et al. reported that both fucoxanthin and fucoxanthinol (10-40 $\mu \mathrm{M})$ induced caspase-dependent apoptosis in human breast cancer cell lines MCF-7 and MDA-MB-231 (31, 32). Fucoxanthinol, but not fucoxanthin, reduced the expression of members of the NF-kB pathway such as p65, p52 and RELB proto-oncogene in MDAMB-231 cells alone, which are estrogen-resistant.

Liu et al. observed that fucoxanthin (1-10 $\mu \mathrm{M})$ enhanced cisplatin-induced apoptosis and attenuated cisplatin-induced NF- $\mathrm{kB}$ activation, resulting in an increase in the BAX/BCL2 ratio in $\mathrm{HepG}_{2}$ cells (33). Fucoxanthin combined with cisplatin attenuated the expression of DNA repair genes such as ERCC excision repair 1 and thymidine phosphorylase, which led to an improvement in the action of cisplatin.

Other effects. Chung et al. found that fucoxanthin at a concentration that did not have a cytotoxic effect on cells (30 $\mu \mathrm{M}$ ) suppressed the invasion of mouse B16-F10 melanoma cells as measured by a Transwell invasion assay, as well as cell migration in a wound-healing assay, and the adhesion of B16-F10 cells to human umbilical vein endothelial cells stimulated with tumor necrosis factor- $\alpha$ (34). These events were accompanied by a decrease in matrix metallopeptidase 9, CD44 and C-X-C motif chemokine receptor 4 , which are known to play crucial roles in cancer migration and invasion, as well as a reduction in actin fiber formation in the cells.

\section{Fucoxanthin Prevents Cancer Development In Mouse Models}

The cancer-preventative actions of fucoxanthin are summarized in Table I.

Okuzumi et al. found that oral administration of fucoxanthin $(0.005 \%$ in drinking water $)$ significantly 
inhibited $N$-ethyl- $N$ '-nitro- $N$-nitrosoguanidine-induced mouse duodenal carcinogenesis (35). Nishino reported that topical application of fucoxanthin with 12-O-tetradecanoylphorbol 13-acetate completely suppressed skin tumor formation in mouse 2-stage skin carcinogenesis (36). Kim et al. reported that the development of aberrant crypt foci in the colons of mice initiated by 1,2-dimethylhydrazine was significantly suppressed by oral administration of fucoxanthin $(0.01 \%$ in drinking water) (37). Additionally, Nishino et al. reported that fucoxanthin $(0.001 \%$ in drinking water $)$ suppressed spontaneous liver carcinogenesis (38). Das et al. found that oral administration of fucoxanthin $(0.005$ and $0.01 \%$ in drinking water) significantly reduced the number of aberrant crypt foci in azoxymethane-treated mice (39).

Yamamoto et al. reported that fucoxanthin $(150 \mathrm{mg} / \mathrm{kg}$ given by gavage) reduced tumor weight in severe combined immunodeficiency mice inoculated with BCBL-1 cells (primary effusion lymphoma) (13). In a study by Wang et al., fucoxanthin (50 and $100 \mathrm{mg} / \mathrm{kg}$ given by gavage) appeared to inhibit the growth of sarcomas in sarcoma 180 xenograftbearing mice (40). In the sarcoma tissues, caspase-dependent apoptosis was observed, which was accompanied with a decrease in the BCL2 protein. Additionally, a decrease in survivin, vascular endothelial growth factor, epidermal growth factor receptor (EGFR), signal transducer and activator of transcription 3 (STAT3) and phosphorylated STAT3 was observed. The authors supposed that fucoxanthin-induced apoptosis was associated with downregulation of STAT3/EGFR signaling. Kim et al. observed that intraperitoneal injection of fucoxanthin $(0.3 \mathrm{mg} / \mathrm{mouse})$ inhibited the increase in tumor volume in B16F10 melanoma cell-implanted mice (14). Ye et al. found that fucoxanthin (10 and $20 \mathrm{mg} / \mathrm{kg}$ given by gavage) inhibited the growth of tumors in nude mice implanted with HeLa cells (30). Rokkaku et al. reported that fucoxanthin $(200 \mathrm{mg} / \mathrm{kg}$ given by gavage) significantly reduced tumor volume in association with increased apoptotic cells in osteosarcomainoculated mice (41). Furthermore, they observed that lung metastasis decreased in these mice compared to the control.

Chung et al. revealed that intraperitoneal injection of fucoxanthin $(0.1 \mathrm{mg} /$ mouse $)$ inhibited lung metastasis as indicated by a reduction in metastatic foci on the lung surface and reduced metastatic nodule numbers in lung tissues of mice injected with B16-F10 melanoma cells through their tail veins (34).

\section{Conclusion}

Fucoxanthin causes antitumor and anticarcinogenic effects by modulating expression of various cellular molecules and cellular signal transduction pathways. These findings suggest that fucoxanthin could be utilized as a possible cancer-preventative agent in strategies designed to combat human cancer.

\section{References}

1 Matsuno T: Aquatic animal carotenoids. Fish Sci 67(5): 771783, 2001.

2 Peng J, Yuan JP, Wu CF and Wang JH: Fucoxanthin, a marine carotenoid present in brown seaweeds and diatoms: metabolism and bioactivities relevant to human health. Mar Drugs 9(10): 1806-1828, 2011.

3 Takaichi S: Carotenoids in algae: distributions, biosyntheses and functions. Mar Drugs 9(6): 1101-1118, 2011.

4 Sugawara T, Baskaran V, Tsuzuki W and Nagao A: Brown algae fucoxanthin is hydrolyzed to fucoxanthinol during absorption by Caco- 2 human intestinal cells and mice. J Nutr 131(12): 3303-3306, 2001.

5 Hashimoto T, Ozaki Y, Mizuno M, Yoshida M, Nishitani Y, Azuma T, Komoto A, Maoka T, Tanino Y and Kanazawa K: Pharmacokinetics of fucoxanthinol in human plasma after the oral administration of kombu extract. Br J Nutr 107(11): 15661569, 2012.

6 Mikami K and Hosokawa M: Biosynthetic pathway and health benefits of fucoxanthin, an algae-specific xanthophyll in brown seaweeds. Int J Mol Sci 14(7): 13763-13781, 2013.

7 Okuzumi J, Nishino H, Murakoshi M, Iwashima A, Tanaka Y, Yamane T, Fujita Y and Takahashi T: Inhibitory effects of fucoxanthin, a natural carotenoid, on N-Myc expression and cell cycle progression in human malignant tumor cells. Cancer Lett 5(1): 75-81, 1990.

8 Das SK, Hashimoto T, Shimizu K, Yoshida T, Sakai T, Sowa Y, Komoto A and Kanazawa K: Fucoxanthin induces cellcycle arrest at $\mathrm{G}_{0} / \mathrm{G}_{1}$ phase in human colon carcinoma cells through up-regulation of $\mathrm{p} 21^{\mathrm{WAF} 1 / \mathrm{CIP} 1}$. Biochim Biophys Acta 1726(3): 328-335, 2005.

9 Das SK, Hashimoto T and Kanazawa K: Growth inhibition of human hepatic carcinoma $\mathrm{HepG}_{2}$ cells by fucoxanthin is associated with down-regulation of cyclin D. Biochim Biophys Acta 1780(4): 743-749, 2008.

$10 \mathrm{Yu}$ RX, Hu XM, Xu SQ, Jiang ZJ and Yang W: Effects of fucoxanthin on proliferation and apoptosis in human gastric adenocarcinoma MGC-803 cells via JAK/STAT signal pathway. Eur J Pharmacol 657(1-3): 10-19, 2011.

11 Ishikawa C, Tafuku S, Kadekaru T, Sawada S, Tomita M, Okudaira T, Nakazato T, Toda T, Uchihara JN, Taira N, Ohshiro K, Yasumoto T, Ohta T and Mori N: Anti-adult T-cell leukemia effects of brown algae fucoxanthin and its deacetylated product, fucoxanthinol. Int J Cancer 123(11): 2702-2712, 2008.

12 Tafuku S, Ishikawa C, Yasumoto $\mathrm{T}$ and Mori N: Antineoplastic effects of fucoxanthin and its deacetylated product, fucoxanthinol, on Burkitt's and Hodgkin's lymphoma cells. Oncol Rep 28(4): 1512-1518, 2012.

13 Yamamoto K, Ishikawa C, Katano H, Yasumoto T and Mori $\mathrm{N}$ : Fucoxanthin and its deacetylated product, fucoxanthinol, induce apoptosis of primary effusion lymphomas. Cancer Lett 300(2): 225-234, 2011.

14 Kim KN, Ahn G, Heo SJ, Kang SM, Kang MC, Yang HM, Kim D, Roh SW, Kim SK, Jeon BT, Park PJ, Jung WK and Jeon YJ: Inhibition of tumor growth in vitro and in vivo by fucoxanthin against melanoma B16F10 cells. Environ Toxicol Pharmacol 35(1): 39-46, 2013. 
15 Wang L, Zeng Y, Liu Y, Hu X, Li S, Wang Y, Li L, Lei Z and Zhang Z: Fucoxanthin induces growth arrest and apoptosis in human bladder cancer T24 cells by up-regulation of p21 and down-regulation of mortalin. Acta Biochim Biophys Sinica 46(10): 877-884, 2014.

16 Liu CL, Huang YS, Hosokawa M, Miyashita K and Hu ML: Inhibition of proliferation of a hepatoma cell line by fucoxanthin in relation to cell-cycle arrest and enhanced gap junctional intercellular communication. Chem Biol Interact 82(2-3): 165172,2009

17 Hou LL, Gao C, Chen L, Hu GQ and Xie SQ: Essential role of autophagy in fucoxanthin-induced cytotoxicity to human epithelial cervical cancer HeLa cells. Acta Pharmacologica Sinica 34(11): 1403-1410, 2013.

18 Satomi Y and Nishino H: Fucoxanthin, a natural carotenoid, induces $\mathrm{G} 1$ arrest and GADD45 gene expression in human cancer cells. In Vivo 21(2): 305-309, 2007.

19 Satomi $\mathrm{Y}$ and Nishino H: Implication of mitogen-activated protein kinase in the induction of G1 cell-cycle arrest and GADD45 expression by the carotenoid fucoxanthin in human cancer cells. Biochim Biophys Acta 1790(4): 260-266, 2009.

20 Satomi Y: Fucoxanthin induces $G A D D 45 A$ expression and $\mathrm{G}_{1}$ arrest with SAPK/JNK activation in LNCap human prostate cancer cells. Anticancer Res 32(3): 807-813, 2012.

21 Kotake-Nara E, Kushiro M, Zhang H, Sugawara T, Miyashita K and Nagao A: Carotenoids affect proliferation of human prostate cancer cells. J Nutr 131(12): 3303-3306, 2001.

22 Kotake-Nara E, Terasaki M and Nagao A: Characterization of apoptosis induced by fucoxanthin in human promyelocytic leukemia cells. Biosci Biotechnol Biochem 69(1): 224-227, 2005.

23 Kotake-Nara E, Asai A and Nagao A: Neoxanthin and fucoxanthin induce apoptosis in PC-3 human prostate cancer cells. Cancer Lett 220(1): 75-84, 2005.

24 Hosokawa M, Kudo M, Maeda H, Kohno H, Tanaka T and Miyashita K: Fucoxanthin induces apoptosis and enhances the antiproliferative effect of the PPAR $\gamma$ ligand, troglitazone, on colon cancer cells. Biochim Biophys Acta 1675(1-3): 113-119, 2004.

25 Konishi I, Hosokawa M, Sashima T, Kobayashi H and Miyashita $\mathrm{K}$ : Halocynthiaxanthin and fucoxanthinol isolated from Halocynthia roretzi induce apoptosis in human leukemia, breast and colon cancer cells. Comp Biochem Phys C Toxicol Pharmacol 142(1-2): 53-59, 2006.

26 Moreau D, Tomasoni C, Jacquot C, Kaas R, Le Guedes R, Cadoret JP, Muller-Feuga A, Kontiza I, Vagias C, Roussis V and Roussakis C: Cultivated microalgae and the carotenoid fucoxanthin from Odontella aurita as potent antiproliferative agents in bronchopulmonary and epithelial cell lines. Environ Toxicol Pharmacol 22(1): 97-103, 2006.

27 Zhang Z, Zhang P, Hamada M, Takahashi S, Xing G, Liu J and Sugiura N: Potential chemoprevention effect of dietary fucoxanthin on urinary bladder cancer EJ-1 cell line. Oncol Rep 20(5): 1099-1103, 2008.

28 Kim KN, Heo SJ, Kang SM, Ahn G and Jeon JY: Fucoxanthin induces apoptosis in human leukemia HL-60 cells through a ROS-mediated BCL-xL pathway. Toxicol In Vitro 24(6): 1648$1654,2010$.

29 Ganesan P, Noda K, Manabe Y, Ohkubo T, Tanaka Y, Maoka T, Sugawara T and Hirata T: Siphonaxanthin, a marine carotenoid from green algae, effectively induces apoptosis in human leukemia (HL-60) cells. Biochim Biophys Acta 1810(5): 497-503, 2011.
30 Ye G, Lu Q, Zhao W, Du D, Jin L and Liu Y: Fucoxanthin induces apoptosis in human cervical cancer cell line HeLa via PI3K/AKT pathway. Tumor Biol 35(11): 11261-11267, 2014.

31 Rwigemera A, Mamelona J and Martin LJ: Inhibitory effects of fucoxanthinol on the viability of human breast cancer cell lines MCF-7 and MDA-MB-231 are correlated with modulation of the NF-kB pathway. Cell Biol Toxicol 30(3): 157-167, 2014.

32 Rwigemera A, Mamelona J and Martin LJ: Comparative effects between fucoxanthinol and its precursor fucoxanthin on viability and apoptosis of breast cancer cell lines MCF-7 and MDA-MB231. Anticancer Res 35(1): 207-219, 2015.

33 Liu CL, Lim YP and Hu ML: Fucoxanthin enhances cisplatininduced cytotoxicity via NFKB-mediated pathway and downregulates DNA repair gene expression in human hepatoma $\mathrm{HepG}_{2}$ cells. Mar Drugs 11(1): 50-66, 2013.

34 Chung TW, Choi HJ, Lee JY, Jeong HS, Kim CH, Joo M, Choi JY, Han CW, Kim SY, Choi JS and Ha KT: Marine algal fucoxanthin inhibits the metastatic potential of cancer cells. Biochem Biophys Res Commun 439(4): 580-585, 2013.

35 Okuzumi J, Takahashi T, Yamane T, Kitao Y, Inagake M, Ohya K, Nishino H and Tanaka Y: Inhibitory effects of fucoxanthin, a natural carotenoid, on N-ethyl-N'-nitro-N-nitrosoguanidineinduced mouse duodenal carcinogenesis. Cancer Lett 68(2-3): 159-168, 1993.

36 Nishino H: Cancer chemoprevention by natural carotenoids and their related compounds. J Cell Biochem Suppl 22: 231-235, 1995.

37 Kim JM, Araki S, Kim DJ, Park CB, Takasuka N, BabaToriyama H, Ota T, Nir Z, Khachik F, Shimidzu N, Tanaka Y, Osawa T, Uraji T, Murakoshi M, Nishino $\mathrm{H}$ and Tsuda $\mathrm{H}$ : Chemopreventive effects of carotenoids and curcumins on mouse colon carcinogenesis after 1,2-dimethylhydrazine initiation. Carcinogenesis 9(1): 81-85, 1998.

38 Nishino H, Murakoshi M, Tokuda H and Satomi Y: Cancer prevention by carotenoids. Arch Biochem Biophys 483(2): 165$168,2009$.

39 Das SK, Hashimoto T, Baba M, Nishino H, Komoto A and Kanazawa K: Japanese kelp (kombu) extracts suppressed the formation of aberrant crypt foci in azoxymethane challenged mouse colon. J Clin Biochem Nutr 38: 119-125, 2006.

40 Wang J, Chen S, Xu S, Yu X, Ma D, X Hu and Cao X: In vivo induction of apoptosis by fucoxanthin, a marine carotenoid, associated with down-regulating STAT3/EGFR signaling in sarcoma 180 (S180) xenografts-bearing mice. Mar Drugs 10(9): 2055-2068, 2012.

41 Rokkaku T, Kimura R, Ishikawa C, Yasumoto T, Senba M, Kanaya F and Mori N: Anticancer effects of marine carotenoids, fucoxanthin and its deacetylated product, fucoxanthinol, on osteosarcoma. Int J Oncol 43(4): 1176-1186, 2013.

Received February 17, 2017 Revised March 13, 2017 Accepted March 14, 2017 